\title{
Measurements of transmission in the visible and the IR in the Baltic coastal environment
}

\author{
Denis Dion ${ }^{1 *}$, Lionel Gardenal ${ }^{2}$, Arie de Jong ${ }^{3}$, Henrik Vogel $^{4}$, Yvonick Hurtaud ${ }^{5}$, Karin Stein ${ }^{6}$, \\ Luc Forand ${ }^{1}$ \\ ${ }^{1}$ DRDC Valcartier, Val-Belair, Canada \\ ${ }^{2}$ Nurun Inc., Québec, Qc, Canada \\ ${ }^{3}$ TNO-DSS, The Hague, The Netherlands \\ ${ }^{4}$ DDRE, Copenhagen, Denmark \\ ${ }^{5}$ CELAR, Rennes, France \\ ${ }^{6}$ FGAN-FOM, Ettlingen, Germany
}

\begin{abstract}
A multinational campaign was organized by the NATO SET56 Group to assess transmission in coastal environments: the VAlidation Measurements of Propagation in IR and RAdar (VAMPIRA) experiment. VAMPIRA was conducted in the Baltic Sea, near Surendorf, Germany, from 27 March to 4 April 2004. During VAMPIRA, transmission was measured in the IR and the visible using a diversity of techniques. Transmissometers were installed across Eckernförde Bay, while aerosol measurements were made on the pier using Particle Measurement Systems (PMS), and visibilitymeters were deployed onshore and on a boat. Furthermore, VAMPIRA included point-target tracking experiments using blackbodies mounted on a boat. Some VAMPIRA measurements have already been presented at various symposiums. The purpose of this paper is to compare VAMPIRA transmission measurements and make comparisons with transmission estimates that can be deduced from the blackbody tracking sessions.
\end{abstract}

Keywords: IR propagation, marine boundary layer, EO system performance

\section{INTRODUCTION}

Due to the increasing importance of coastal operations for the Navies of the Western world, it has been of increasing interest to improve knowledge about EO system performance and efficiency in these environments. Propagation effects, particularly transmission, are more difficult to predict in the littoral when compared to the open sea, due to significantly high temporal and spatial variations. Furthermore, in the littoral, conditions can depend strongly on the geographical location, the topography of the land, and even the surrounding human activity. In order to assess propagation effects on sensors (both EM and EO), the NATO SET56 Group organized a measurement campaign in the Baltic at the entrance of Eckernförde Bay near Surendorf, Germany (see Fig. 1) in Spring 2004: the VAlidation Measurements of Propagation in IR and RAdar (VAMPIRA) [1]. The experiment took place at LBTS Surendorf and was hosted by WTD71 - Technical Center for Ships and Naval Weapons. Although the main objective of VAMPIRA was to study the complementarity of IR and radar systems, it provides at the same time a valuable dataset on transmission and propagation in the Baltic littoral.

The purpose of this paper is to compare transmission measurements performed during VAMPIRA in the mid-wave IR (MWIR) and the visible. This study shows the variability of conditions in the area. It highlights the difficulty in obtaining an accurate description of transmission in such a dynamic environment. The study focuses on 12 outbound sorties of the German boat Stollergrund. In Section 1, meteorological conditions during the sorties are surveyed by examining measurements obtained from various teams and various locations. One objective of this paper is to propose a consensus description of the conditions for future propagation studies and model validation. Measurements of

*Denis.Dion@drdc-rddc.gc.ca ; phone: 418 -844-4000, ext. 4231, fax: 418-844-4511

Optics in Atmospheric Propagation and Adaptive Systems $X$

edited by Karin Stein, Anton Kohnle, John D. Gonglewski, Proc. of SPIE

Vol. 6747, 67470X, (2007) · 0277-786X/07/\$18 - doi: 10.1117/12.742342

Proc. of SPIE Vol. 6747 67470X-1 
transmission are presented in Section 2. Results are discussed in Section 3 where lessons learned are summarized, and Section 4 draws the main conclusions.

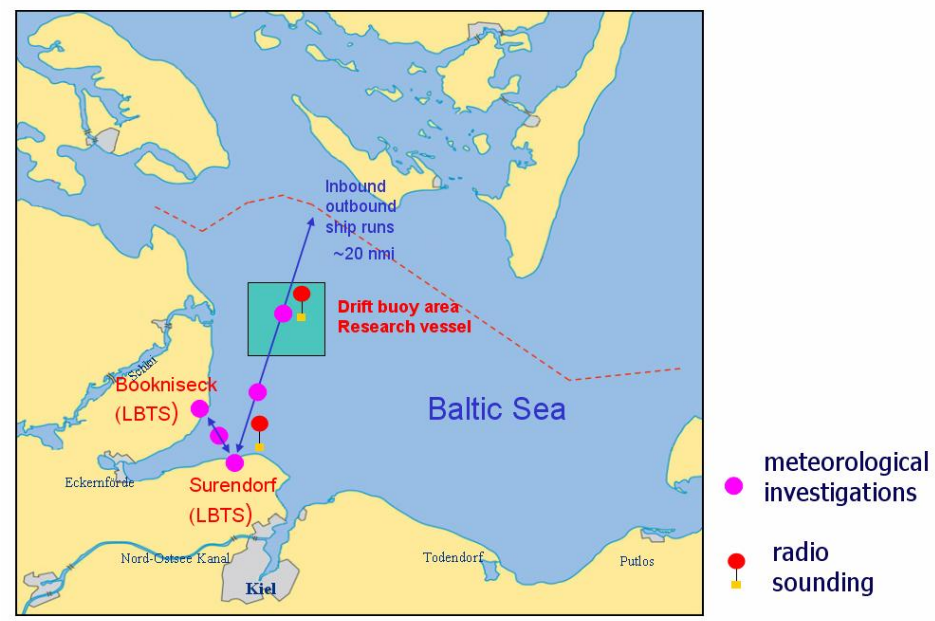

Fig 1 - The VAMPIRA experimental site

\section{METEOROLOGICAL CONDITIONS}

To measure meteorological conditions above water, TNO (the Netherlands) moored a buoy they fabricated in the Eckernförde Bay at about mid-path between Surendorf and Bookniseck, and FWG (Germany) deployed fix and drift meteorological buoys along with a wave buoy at sea during most of the Stollergrund sorties. Figure 1 shows the location of the buoys. As a complement, Germany (WTD and FGAN), Canada and the Netherlands performed measurements on the pier of Surendorf and on the hill of Bookniseck using standard equipments. France also installed a meteorological station on the hill at Surendorf.

The main meteorological parameters of interest for propagation studies are the air and water temperatures, the humidity, and the wind speed and direction. Analysis was done for the 12 outbound sorties of the German boat Stollergrund.

Water temperature. Measurements obtained from the two FWG buoys perfectly match in all cases (the two buoys were always very close to each other). The FWG measurements agree with TNO buoy measurements at the entrance of the bay, except on 3 April when the bay water temperature is reported to be about 0.6 degree warmer than at sea. Furthermore, for the first 2 days, TNO measurements are slightly lower than FWG's (about 0.2-0.3 C). A likely reason is that the TNO probe was $1 \mathrm{~m}$ below the surface; the actual surface (skin) temperature may likely be somewhat greater during these mostly sunny days; the depth of the FWG probes is $10 \mathrm{~cm}$ below the surface. Warmer waters are generally measured at the Pier. As it is believed to represent a local condition very near the shore, these measurements were not considered in the analysis. Figure 2 shows the 25 March measurements. In the Figures, the rectangles indicate the periods of the sorties.

Air temperature. Although the TNO buoy was equipped with sensors to provide measurements at various heights, in our analysis we considered only the higher measurements $5.2-\mathrm{m}$ above the surface. The height of the FWG air temperature sensor was about the same. TNO buoy measurements were always systematically smaller than FWG temperature by more than 0.5 degree C. Interestingly, based on their observations of scintillation across the bay, Dion et al. [2] had suggested that the actual air temperature across the bay should likely be about 0.8 degree $\mathrm{C}$ greater than reported by the TNO buoy. Measurements for 27 March are shown in Fig. 3. In general, pier and land measurements, which were made at a higher elevation (about $10 \mathrm{~m}$ ), agree very well with each other and they appear to be somewhat greater than above water during the entire experiment (as observed in Fig. 3). Note that the diurnal variation of the French measurements is more significant, as their station was more in-land. We can conclude that, like for the water 
temperature, the air temperatures in the bay and at sea were relatively uniform. The same can therefore be said about the Air-Sea Temperature Difference (ASTD). An exception occurred on the last day (3 April) when the TNO buoy measurements were about $2 \mathrm{C}$ greater than FWG's; measurements on the pier and on land agree with this trend. The conditions on 3 April are clearly stable with the wind coming from the land (e.g. SSE).

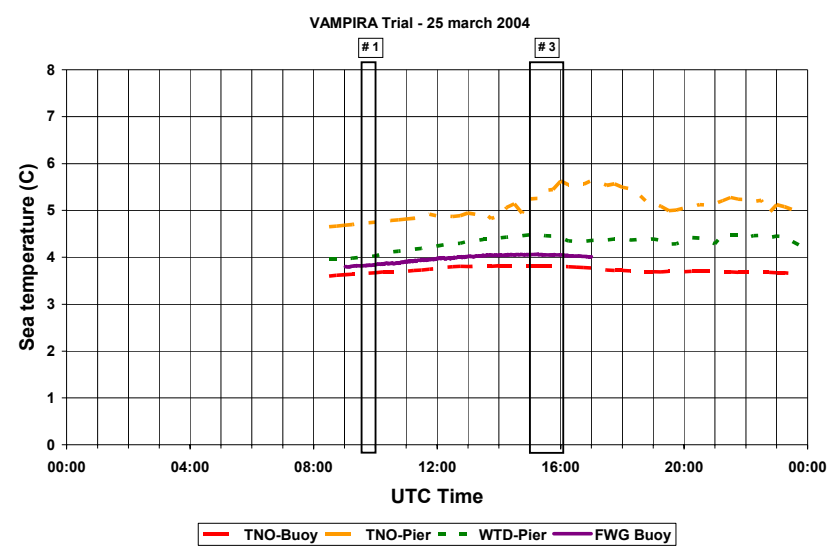

Fig 2 - Water temperature measurements on 25 March

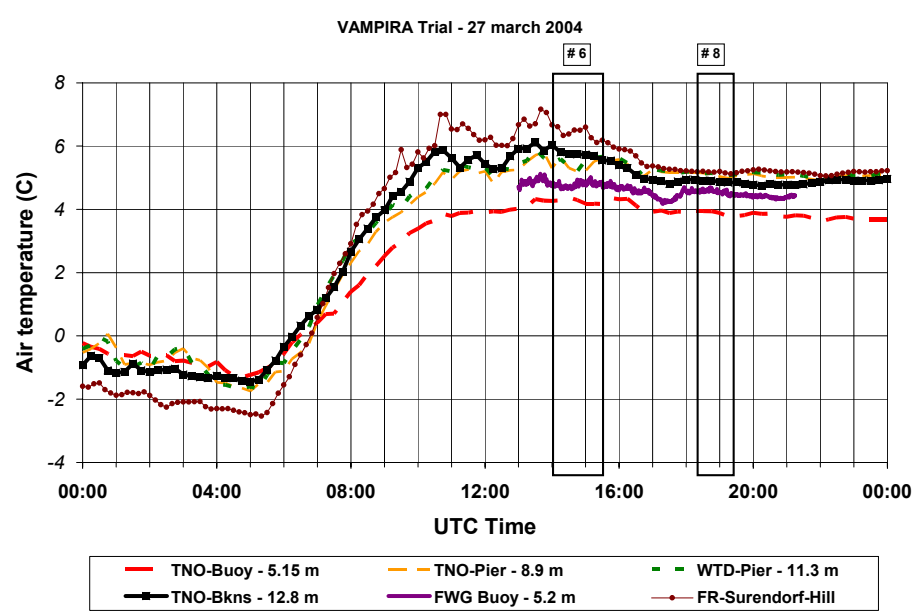

Fig 3 - Air temperature measurements on 27 March

Relative humidity. All relative humidity measurements closely agree during all sorties, except on 3 April. On that day, following a significant drop over the bay in early morning, the relative humidity in the bay was seen to be about $15 \%$ lower than at sea during the mid-day sorties (65\% compared with $80 \%)$. As with temperature, uniform conditions can be concluded across the period of VAMPIRA except for the 3 April sorties.

Wind speed and direction. Unlike the temperature and humidity measurements, wind speed measurements differ greatly from one location to another in most cases. On 25 and 26 March, when the wind comes from sea (50 degrees), the measurements at sea $(=5 \mathrm{~m} / \mathrm{s})$ agree with measurements at Booknisek but can be $1-2 \mathrm{~m} / \mathrm{s}$ different from the pier measurements and the in-land France measurements. By 27 March the wind direction had changed from a sea wind to a land wind. In this case, wind speed at sea $(7 \mathrm{~m} / \mathrm{s})$ agrees better with measurements on the pier; the wind speed on land is $4 \mathrm{~m} / \mathrm{s}$ smaller. Figure 4 shows the 27 March wind speed measurements. A similar trend is observed on 31 March. On 29 March a very light wind is reported by all sensors (about $2 \mathrm{~m} / \mathrm{s}$ or less). Understandably, measurements of wind 
directions under these conditions are somewhat erratic. On 1 April, measurements were unfortunately not performed at sea and large discrepancies were obtained throughout the day with all probes in the bay, ranging from about 5 to $9 \mathrm{~m} / \mathrm{s}$. Figure 5 shows the 1 April wind speed measurements. It is worth noting that from 31 March on, wind direction was along the coast (SE: 100-150 degrees). On 3 April, wind speeds at sea are somewhat stronger than in the bay $(5 \mathrm{~m} / \mathrm{s}$ compared to $3 \mathrm{~m} / \mathrm{s}$ ), where all probes tend to agree.

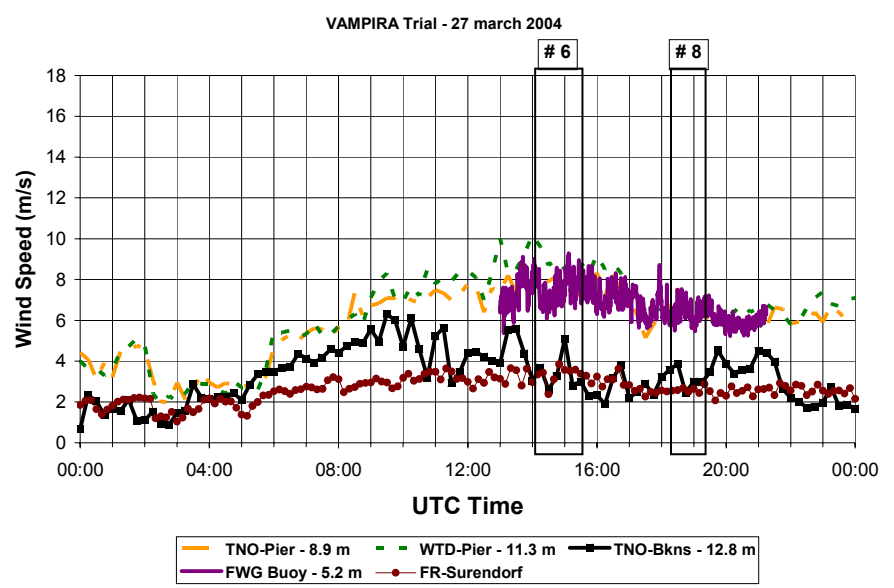

Fig 4 - Wind speed measurements on 27 March

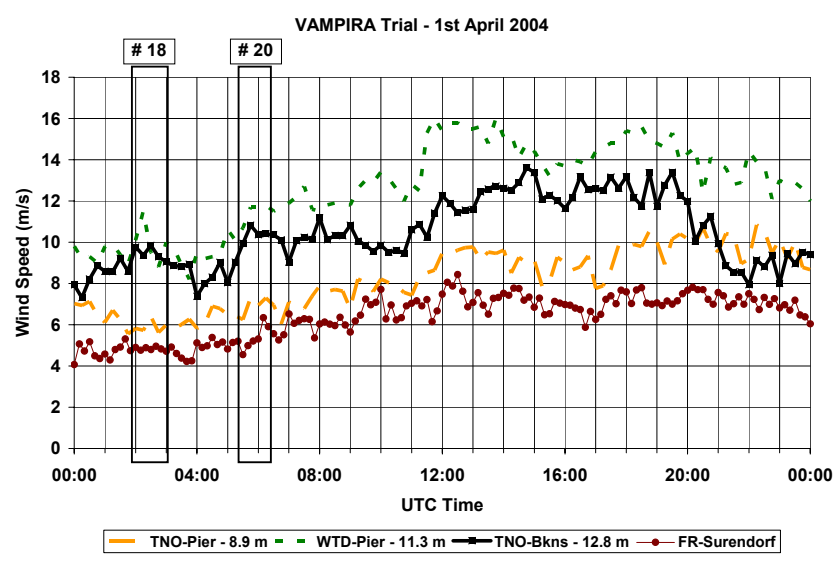

Fig 5 - Wind speed measurements on 1 April

Consensus meteorological conditions. For the development and validation of propagation models, it is useful to reduce the description of the conditions in a region of interest to a single set of meteorological measurements, hereafter referred to as "consensus conditions". This can be easily done for the temperatures, humidity and wind direction, for all selected Stollergrund sorties (except 3 April sorties), since as discussed above, these proved to be fairly uniformed in the region. For the wind speed, it was decided to use measurements at sea whenever available as these are likely to be the most representative along the boat path and also less vulnerable to obstructions. For $1^{\text {st }}$ April sorties, we privilege the measurements made at Bookniseck, as they are likely to be more representative of the conditions at sea. On 3 April, the 
conditions at sea and in the bay are difficult to conciliate. For our consensus conditions we chose the conditions at sea. Table 1 shows the consensus meteorological conditions for the 12 Stollergrund outbound sorties. The run numbers correspond to the official VAMPIRA run identification.

Table 1 - Consensus meteorological conditions

\begin{tabular}{|c|c|c|c|c|c|c|c|c|c|}
\hline Run & Time & TA & TS & ASTD & RH & WS & WS24 & WD & Tide \\
\hline$\#$ & (UTC) & $($ C) & $($ C) & $($ C) & $(\%)$ & $(\mathrm{m} / \mathrm{s})$ & $(\mathrm{m} / \mathrm{s})$ & $(\mathrm{deg}$. thru N) & $(\mathrm{m})$ \\
\hline 1 & $25 / 3-9: 30$ & 1.7 & 3.8 & -2.1 & 69 & 6 & 6.5 & 50 & 0.1 \\
\hline 3 & $25 / 3-15: 00$ & 3.3 & 4.1 & -0.8 & 65 & 4.6 & 5.0 & 50 & 0.1 \\
\hline 4 & $26 / 3-12: 00$ & 1.9 & 4.0 & -2.1 & 62 & 4.6 & 5.1 & 50 & 0.05 \\
\hline 6 & $27 / 3-14: 00$ & 4.8 & 3.8 & 1.0 & 76 & 7.7 & 3.7 & 250 & -0.4 \\
\hline 8 & $27 / 3-18: 21$ & 4.6 & 3.9 & 0.7 & 90 & 6.5 & 6.8 & 250 & -0.5 \\
\hline 10 & $29 / 3-16: 52$ & 7.3 & 4.8 & 2.5 & 85 & 1.2 & 5 & - & -0.3 \\
\hline 12 & $29 / 3-20: 20$ & 6.4 & 4.8 & 1.6 & 87 & 2 & 1 & 110 & -0.2 \\
\hline 14 & $31 / 3-00: 35$ & 5.2 & 4.8 & 0.4 & 88 & 5.4 & 4.1 & 110 & -0.1 \\
\hline 16 & $31 / 3-22: 02$ & 6.1 & 4.9 & 1.2 & 86 & 7.5 & 6.5 & 110 & 0.0 \\
\hline 18 & $01 / 4-01: 50$ & 5.4 & 4.1 & 1.3 & 88 & 9.8 & 8 & 110 & 0.25 \\
\hline 20 & $01 / 4-5: 12$ & 5.2 & 4.1 & 1.1 & 91 & 10 & 8 & 110 & 0.25 \\
\hline 21 & $03 / 4-8: 25$ & 5.0 & 4.3 & 0.7 & 78 & 4 & 8 & 150 & -0.1 \\
\hline
\end{tabular}

TA: Air temperature ; TS: Sea temperature; RH: Relative Humidity; WS: Wind speed; WS24: 24-hr average WS; WD: Wind direction

\section{TRANSMISSION MEASUREMENTS}

During VAMPIRA, TNO performed measurements of aerosol size distributions (ASD) from the Surendorf pier, from which extinction can be calculated using Mie theory. In addition, TNO deployed a Multi-Spectral Radiometer Transmissometer (MSRT) across the bay between Surendorf and Bookniseck (see Fig. 1). Revision of their MSRT data was recently published [3]. In our paper, we consider the MSRT measurements of channel $2(0.57-0.65 \mu \mathrm{m})$ and $6(3.55-$ $4.15 \mu \mathrm{m})$. We believe that taken together, the TNO ASD and Transmissometer datasets provide a valid description of aerosol extinction in the bay throughout the campaign.

Visibility was measured by France and Germany (WTD) at Surendorf and by Canada on the boat, using visibility meters. France used the VAISALA FS11 system while Canada used the HSS visibility meter. The output signal of these instruments is proportional to the extinction coefficient at $0.55 \mu \mathrm{m}$. A shortcoming of visibility meters is that they are not sensitive enough to provide trustful measurements under good visibility conditions. We think that they are the most reliable when visibilities are shorter than $30 \mathrm{~km}$. Table 2 shows the various visibilities obtained from the respective teams during the Stollergrund outbound runs. In Table 2, the visibility in $\mathrm{km}$ is taken to be $3 / \beta$, where $\beta$ (in $\mathrm{km}^{-1}$ ) is the extinction coefficient ${ }^{*}$. The visibility across the bay as deduced from the MSRT channel 2 (using the same relationship with $\beta$ ) is also given for comparison. It is worth noting that all measurements agree very well under the low visibility conditions. By examining the overall period of VAMPIRA we found that Canada and France measurements agree very well most of the time when the visibilities are shorter than $30 \mathrm{~km}$ and the boat does not move. Measurements of 26 March shown in Fig. 6 provide a good example. Very large fluctuations and variations of extinctions are obtained with the HSS at sea in many cases (e.g. sorties 1, 3, 4, 10, 12 and 20). In the future, it is recommended that the boat be stopped at sea to improve the quality of measurements. We chose the French measurements for the consensus visibilities.

\footnotetext{
${ }^{*}$ This expression is often called « observed » visibility, as opposed to the more widespread expression $\mathrm{V}=3.914 /(\beta+0.0116)$, known as "instrumented" visibility.
} 
Table 2 - Measured extinction in the visible in terms of visibility $(\mathrm{km})$

\begin{tabular}{|c|c|c|c|c|c|}
\hline Run & Canada & France & WTD & MSRT & Consensus \\
\hline 1 & 80 & 50 & $(1)$ & $(2)$ & $>30$ \\
\hline 3 & 70 & 43 & $(1)$ & 60 & $>30$ \\
\hline 4 & 80 & 65 & $(1)$ & 60 & $>30$ \\
\hline 6 & 40 & 40 & 19 & 43 & $>30$ \\
\hline 8 & 15 & 20 & 15 & 38 & 20 \\
\hline 10 & 15 to 80 & 23 & 13 & 27 & 23 \\
\hline 12 & 15 to 40 & 21 & 11 & 27 & 21 \\
\hline 14 & 10 & 10 & 10 & 15 & 10 \\
\hline 16 & 8 & 8 & 8 & 9 & 8 \\
\hline 18 & 5 & 5 & 5 & 9 & 5 \\
\hline 20 & 5 to 20 & 7 & 7 & 10 & 7 \\
\hline 21 & 17 & 17 & 15 & 33 & 17 \\
\hline
\end{tabular}

(1) Clipped to $23 \mathrm{~km}$; (2) not available

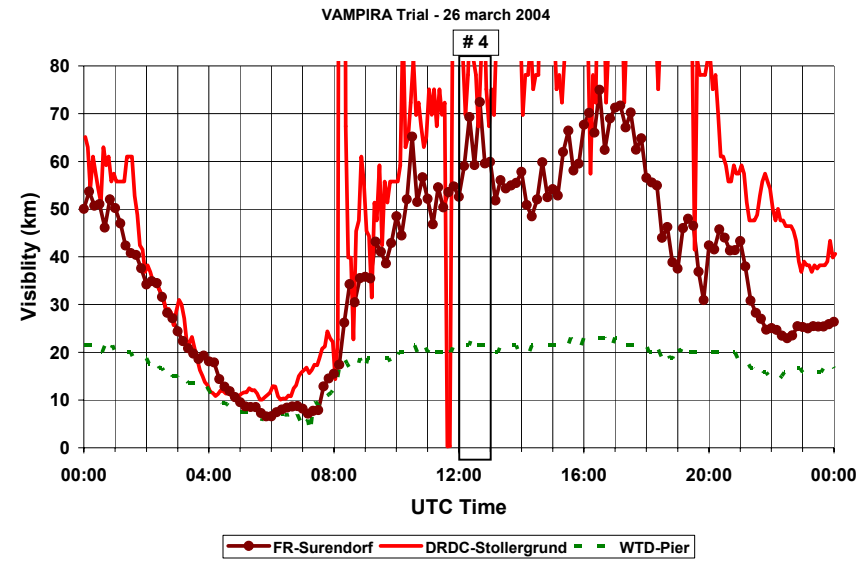

Fig 6 - Visibility measurements on 26 March

Denmark, France and Germany (FGAN) conducted point target detection experiments in the IR using blackbodies installed on the Stollergrund. All teams performed calibrated measurements taking proper care of sensor gain control and integration time. Transmission along the Stollergrund path can be deduced from their respective measurements by analyzing variation of received target signals (or target-background contrast signals) versus range. Comparing measurements of the three countries is instructive, as their systems differ greatly with regard to the waveband, resolution and sensitivity. Table 3 shows the waveband and resolution of the three systems. All systems were installed about $18 \mathrm{~m}$ above the mean water level.

Table 3 - Camera specifications

\begin{tabular}{|c|c|c|c|}
\hline TEAM & CAMERA & WAVEBAND $(\mu \mathrm{m})$ & IFOV $(\mathrm{mrad})$ \\
\hline DDRC (Denmark) & SBF InSb & $3.6-4.1$ & 0.06 \\
\hline CELAR (France) & CEDIP InSb & $3.7-5.1$ & 0.15 \\
\hline FGAN( Germany) & AIM GaAs QWIP & $4.4-5.2$ & 0.24 \\
\hline
\end{tabular}


Although two blackbodies were mounted on each side of the Stollergrund, only the 200 degree C blackbody mounted on the port side was considered in our analysis. Analysis over relatively long range is required to determine extinction especially under low extinction situations (in order to accumulate a measurable optical depth). For the retrieval of extinction, the analysis of received signals focused on the range interval $5-15 \mathrm{~km}$, when possible. Beyond $15 \mathrm{~km}$, refraction can affect transmission depending on the ASTD, as observed by most teams. Using high-resolution, as done by Denmark, is more than suitable in order to reduce ambiguities (by ensuring target image a sufficient size at long range). Figure 7 clearly shows the exponential decrease of the signal measured in the mid-wave IR by Denmark during run \#16. On log-linear graphics, the slope of signal variation corresponds to the effective attenuation along the path.

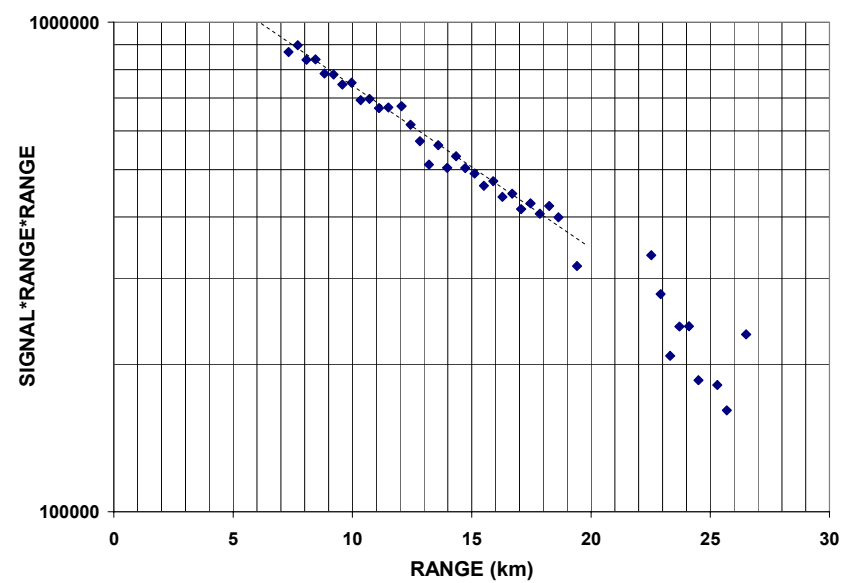

Fig 7 - Danish radiometric measurements in the mid-wave IR during sortie \#16

France considered various techniques for extracting target signals at a given range from their recorded images [4]. The technique that provides the best information on signal decrease with range consists of (1) averaging pixel signals over a 50-image sequence ( $2 \mathrm{sec}$ ) and (2) considering the greatest of all only (to avoid dilution of target signal in background). Applying temporal averaging allows one to smooth out fluctuations due to turbulence. Germany also applied various methods of analysis. Extinctions presented here were obtained by summing target pixel signals after discriminating the target pixels from background pixels.

Due to the low resolution of the France system, the target subtend angle gets rapidly smaller than the Instantaneous Field-of-View (IFOV) of the system as the target goes away from the observer. As a result, the target pixel gets rapidly dominated by the background signal, even though the target-background radiance difference is relatively good. In order to capture the extinction over an acceptable range interval, under sub-pixel situations, transmittances were obtained for any given range using:

$$
\tau_{F}=\frac{S-N_{b g}\left(1-r_{a}\right)}{N_{b b} \cdot r_{a}}
$$

where $S$ is the target signal (calibrated in radiance units), $r_{a}$ is the ratio between the apparent target area and the pixel subtend area at the target range, and $N_{b g}$ and $N_{b b}$ are the background and blackbody radiances respectively. Correcting for sub-pixel situations was not deemed necessary for the Denmark measurements owing to the good resolution. It can be demonstrated that in the worst situations, the correction would increase the transmission by only $20-25 \%$. No correction was made on German measurements.

Transmission measurements are compared considering the extinction caused by aerosols. It is obtained by subtracting the gaseous extinctions computed at various ranges using MODTRAN. We verified that the path radiance could be neglected in the process. The gaseous extinction differs depending on the system waveband widths (see Table 3), but it 
does not vary very much from one sortie to the other. The variation of the gaseous extinction coefficients (estimated at $10 \mathrm{~km}$ ) throughout the experiment is respectively 0.030-0.036 for Denmark, 0.10-0.12 for France and 0.17-0.22 for Germany. For the outbound Stollergrund sorties, Table 4 shows the extinction coefficients in the mid-wave IR obtained from the Denmark, France and Germany tracking measurements, together with the extinction obtained from channel 6 of the MSRT, and the extinction derived from the ASD measurements on the pier. For comparison, the consensus extinction in the visible (corresponding to the consensus visibility shown in Table 2) is also given.

A Particle Volume Monitor (PVM) by Gerber Scientific, Inc. was installed on the boat by Canada as another means to provide measurements of extinction in the mid-wave IR. The PVM is a laser-diffraction particle-sizing instrument that is designed and configured to give estimates of the extinction coefficient at a wavelength of $3.75 \mu \mathrm{m}$ [5]. Unfortunately, extinctions obtained with the PVM raised suspicions for several reasons:

- In most cases, notably on the first days, strong extinctions (0.11) are measured on the boat at the start of the sorties when the boat is in the bay, not far away from the PMS and the MSRT systems;

- The measured extinctions exhibit very large fluctuations and variations during the sorties;

- Measurements seem to be unrealistically affected by humidity and visibility; this dependency is not observed on MSRT measurements;

- In many cases, notably for the sorties of 26 March and 3 April, extinctions are significantly different during the out and inbound runs of the Stollergrund although the runs were carried out one right after the other and with no appreciable change of meteorological conditions. (Inboundrun extinctions proved to be much weaker.)

Extinctions obtained with the PVM during the Stollergrund sorties are also presented in Table 4 for information.

Table 4 - Measured extinction coefficients $(1 / \mathrm{km})$ - aerosol contribution

\begin{tabular}{|c|c||c|c|c|c|c|c||}
\hline RUN & $\begin{array}{c}\text { Consensus } \\
0.55\end{array}$ & $\begin{array}{c}\text { MSRT } \\
3.75 \mu \mathrm{m}\end{array}$ & $\begin{array}{c}\text { PMS } \\
4 \mu \mathrm{m}\end{array}$ & $\begin{array}{c}\text { Denmark } \\
3.6-4.1 \mu \mathrm{m}\end{array}$ & $\begin{array}{c}\text { France } \\
3.7-5.1 \mu \mathrm{m}\end{array}$ & $\begin{array}{c}\text { Germany } 1 \\
4.4-5.2 \mu \mathrm{m}\end{array}$ & $\begin{array}{c}\text { Gerber } \\
3.75 \mu \mathrm{m}\end{array}$ \\
\hline 1 & $<0.1$ & $(1)$ & 0.01 & 0.04 & $(1)$ & 0.03 & .11 \\
\hline 3 & $<0.1$ & 0.02 & 0.01 & 0.01 & 0.02 & 0.03 & $0.07-0.15$ \\
\hline 4 & $<0.1$ & 0.01 & 0.01 & $(2)$ & $(2)$ & $(2)$ & $0.11-0.36$ \\
\hline 6 & $<0.1$ & 0.01 & 0.01 & 0.11 & 0.12 & 0.17 & 0.08 \\
\hline 8 & 0.15 & 0.03 & 0.03 & 0.03 & 0.05 & $(2)$ & $0.1-0.28$ \\
\hline 10 & 0.13 & 0.03 & 0.02 & 0.02 & 0.04 & 0.03 & $(2)$ \\
\hline 12 & 0.14 & 0.04 & 0.02 & 0.03 & $(1)$ & $(1)$ & 0.02 \\
\hline 14 & 0.30 & 0.02 & 0.03 & 0.03 & 0.03 & 0.02 & 0.04 \\
\hline 16 & 0.38 & 0.04 & 0.03 & 0.04 & 0.06 & 0.06 & 0.11 \\
\hline 18 & 0.60 & 0.05 & 0.06 & 0.05 & 0.03 & 0.05 & 0.14 \\
\hline 20 & 0.43 & 0.05 & 0.07 & 0.05 & 0.05 & 0.06 & 0.14 \\
\hline 21 & 0.18 & 0.01 & $(1)$ & 0.06 & 0.07 & $(2)$ & $0.02-0.1$ \\
\hline
\end{tabular}

(1) Data unavailable or insufficient; (2) Lack of sensitivity

\section{DISCUSSION}

The two-week period of VAMPIRA provided transmission data under both thermally stable and unstable situations with an appreciable variation of wind speed and visibility. Under the unstable situations (sorties \#1, 3 and 4), the meteorological conditions proved fairly uniform over the experimental site, with the wind coming from the sea (wind direction is NE), bringing in marine air. Under stable conditions (all other sorties), the conditions still remain relatively uniform, except maybe during sortie \#10 (29 March) where ASTD at sea was about 1 degree higher than in the bay. However, different conditions in the bay and at sea were observed during sortie \#21, on 3 April, where a rapid drop of humidity occurred in the morning in the bay associated with a significant increase of air temperature (and ASTD). Under the stable situations, the wind measurements above land vary significantly from one location to the other and differ from measurements at sea. 
Among the lessons learned from our survey of meteorological conditions at VAMPIRA it may be worth noting that:

- Measurements of water temperature from a pier are not believed to be representative, especially in the case of a bay;

- Similarly, in coastal regions, in-land measurements of wind speed (and direction) are not likely to be reliable for describing conditions a few kilometers away at sea;

- Small scale synoptic wind speed and direction maps would be very useful to understand the global scene.

Bullet 1 and 2 emphasize the need for at-sea measurements using buoys or boats. When extinction measurements are performed at sea on a boat, the boat shall be requested to stop at a certain number of stations the time for the conditions to settle.

From inspection of Table 4, one notes that weak extinctions $\left(<0.05 \mathrm{~km}^{-1}\right)$ are deduced in the MW IR from the blackbody tracking experiments in most cases. The weakest extinctions are very close to the limit of sensitivity and uncertainty of our analysis of tracking experiments, estimated to be about $0.01 \mathrm{~km}^{-1}$ or perhaps more. The strongest extinctions were obtained from blackbody tracking during sortie \#6. The sortie 6 measurements are puzzling as greater extinctions are obtained in the IR than in the visible, which is in disagreement with Mie scattering theory. Nevertheless, should the visibility at sea be actually slightly less than the consensus visibility, the case would be consistent. (Visibilities at sea of $27 \mathrm{~km}$ would make the case fully consistent.) The measured high extinction can suggest the predominance of marine air at sea, although the situation is reported to be slightly stable. From case 8 onward, the conditions are stable and extinctions along the Stollergrund path are found to be close to extinctions measured in the bay, indicating a strong continental influence. The persistent low extinction measured in the bay suggests that throughout the campaign the conditions in the bay remain pretty continental. This agrees with the results obtained by de Jong et. al [6] who found that measured and deduced aerosol concentrations in the bay agree with the MODTRAN rural model.

Measuring transmission under low-extinction conditions and over long distances is tricky. Local measurements as obtained using PMS on the pier are valid but they are not guaranteed to be representative of the conditions over long distances. This had been pointed out by other authors [5]. Deploying 2-point transmissometers across a large distance is not easy and it is subject to calibration uncertainties. Again, while it may provide valid information about the conditions along the transmission link, it may not provide reliable indications about the conditions further at sea. Our analysis shows that radiometric tracking of blackbodies can provide a valid solution to measure extinction over a long range under relatively low extinction conditions. A neat advantage of this method is that it does not depend on a precise calibration; the information is contained in the rate of decrease of signal. Although a high-resolution system, like the one used by Denmark, is the most suitable, it was interesting to find out that, with some precautions, similar estimations can also be obtained using lower-resolution systems.

\section{CONCLUSIONS}

The VAMPIRA campaign provided valuable data for assessing propagation and transmission in the Baltic coastal environment. The aim of this paper was to characterize transmission in the IR in this area by combining measurements performed by various research teams. The study focuses on outbound sorties of the German boat Stollergrund which provided data at sea. Meteorological conditions that prevailed over the experimental site during the sorties are described in some details, fusing measurements obtained in various locations.

We compared aerosol extinction measurements obtained from different methods and from various locations:

- Multi-Band Transmitter across the bay between Surendorf and Bookniseck

- $\quad$ Particle Measurement System on the pier

- Visibility meters installed on various locations, including onbaord

- Long-range radiometric blackbody tracking. 
Extinctions deduced from aerosol size distribution on the pier are in good agreement with extinctions obtained by the Transmissometer across the bay. Extinction at sea was estimated by analyzing the rate of signal decrease obtained by radiometric imagery of a blackbody mounted on the Stollergrund. Although it is more than suitable to use highresolution system for this purpose to ensure a sufficient level of signal at long ranges, it was interesting to find that good measurements can also be obtained under most situations even with medium resolution systems.

In general, good transmission conditions were observed under most Stollergrund outbound sorties. During most sorties, the conditions were thermally stable. In the bay, the extinctions in the MWIR remained low throughout the experiment even during the low visibility cases and the unstable periods. The aerosol extinction coefficient in the mid-wave IR never exceeded 0.05 in the bay during the sorties. Under most stable situations, the extinctions that were measured at sea and in the bay were close to each other, suggesting that the conditions in the littoral (in the bay and at sea) were driven by continental air.

More experiments are required to understand the variability of extinction in coastal environments. Obtaining accurate measurements represents a major difficulty. This study compares measurements techniques and gives some insights about their sensitivity, accuracy and limits.

\section{REFERENCES}

[1] H.J.M. Heemskerk, VAMPIRA - Radar and Infrared Propagation Synergism Trial, Proceedings of ECPS European Conference on Propagation and Systems, 2006

[2] Dion, D., Seiffer, D., Stein, K., Forand, L and G. Potvin, Raypath deviation under stable and unstable conditions, SPIE Proc, Vol. 5981, 2005

[3] de Jong, A.N., van Eijk, A.M.J., Moerman, M.M. and L.H. Cohen, Aerosol size distributions, retrieved from multiband transmissometer data in the Southern Baltic Sea during the VAMPIRA trials, SPIE Vol. 6364, Sept. 2006

[4] Le Rhun, G. and Y. Hurtaud, Analyse de la campagne VAMPIRA: Mesures et modélisation de la luminance en infrarouge (bande2) de 2 corps noirs embarqués, Rapport technique CELAR, 2007/165001/CELAR/CGN/1703906/NCO

[5] Gerber, H., Direct measurement of suspended particulate volume concentration and far-infrared coefficient with a laser-diffraction instrument, App. Opt. 30 (33), 1991, pp. 4824-4831

[6] de Jong, A.N., Cohen, L.H. and M.M. Moerman, Multi-band optical/IR transmissometry during the VAMPIRA trials, Spring 2004,, SPIE Vol. 5572, Sept. 2004 